\title{
Effects of overtraining and two non-correction training procedures upon a brightness discrimination reversal'
}

\author{
COLEMAN PAUL \\ ADELPHI UNIVERSITY
}

The effects of overleaming and two non-correction training procedures upon the reversal of a black-white discrimination task were investigated. Overtraining and the Non-Entry procedure facilitated reversal learning.

Experiments concerned with learning in a simultaneous discrimination task have used two types of non-correction training procedures. In the Entry (E) procedure an incorrect response is usually defined in terms of the rats entry into the (unbaited) goalbox associated with S-. In the Non-Entry (NE) procedure an incorrect response is usually defined in terms of the rats entry into a "pre-goal area" and/or the pushing against $\mathrm{S}-$, typically a locked door. The E procedure was used by Paul \& Havlena (1965) and versions of the NE procedure were used by Reid (1953) and Mackintosh (1963). Hence in the $\mathrm{E}$ procedure $\mathrm{S}$ enters a goal box following either a correct or an incorrect response, whereas in the NE procedure $S$ enters a goal box only following a correct response.

A group trained under the $\mathrm{E}$ procedure and then given reversal training faces non-reinforcement of the previously correct response; whereas a group trained under the NE procedure is blocked or prevented from making the originally correct response or response chain. On the basis of this observation Paul (1965) speculated that the inconsistent findings with regard to the effect of post-critical trials upon discrimination reversal might be due, in part, to the described differences in training procedures. The present experiment was designed to test the effects of overtraining upon discrimination reversal under the two types of training procedures.

Method

Subjects. Thirty-two male albino rats, weighing about $230 \mathrm{gm}$ on their arrival from Charles River Breeding Laboratories, served as Ss. ${ }^{2}$

Apparatus. A T-maze with a 10-in. gray stem and 20-in. arms was used. The maze was 4 in. wide, 5 in. high and covered with wire screening. One arm of the $T$, up to the center of the choice region was painted white; the other half of the choice region and the other arm was painted black. Twelve and three-quarter in. from the end of each arm there was a one-way swinging door painted the same color as the arm in which it was located. These doors could be locked to prevent $S$ from pushing through them. A small goal dish was attached to the inner end wall of each arm, and was painted the same color as the arm in which it was located. A Tshaped guillotine door separated the stem from the choice region and bisected the choice region. When this door was lowered a 7-in. "pre-goal chamber" was formed between this door and each of the swinging doors. The arms could be shifted to randomize the brightnessposition relation.

Pretraining. Ss were put on an ad lib feeding schedule until they weighed approximately $300 \mathrm{gm}$. They were then starved down to about $85 \%$ ad lib weight and maintained at that level throughout the experiment. Ss were put into the pre-goal chambers until they pushed through the swinging doors; gentle nudging was used if a $S$ failed to push through the doors within $15 \mathrm{~min}$. At least one choice trial was given from the stem. Throughout pretraining no food reinforcement was present in the maze, but Ss were given one day's rations made up of the food pellets which were to be used for reinforcement.

Discrimination training. Ss were assigned to either the Entry (E) or Non-Entry (NE) Groups on a random basis except for the requirement of equal N's per group. $S$ was put into the maze stem and the guillotine door was raised. When $S$ made a whole body turn in either the left or right the guillotine door was lowered, enclosing $S$ in the pre-goal chamber. Group E Ss could push through the swinging door into the goal chamber whether the choice response had been correct or not. Group NE Ss could enter a goal chamber following a correct response; following an incorrect response these Ss were confined in the pre-goal chamber by means of the locked "swinging door." Confinement in either an incorrect goal box or pre-goal chamber was for a period of about 10 sec. The reinforcement for a correct response was three $94 \mathrm{mg}$ Noyes pellets. Ss were given 10 trials per day with an intertrial interval of about $10 \mathrm{~min}$. All Ss were trained with white as the positive stimulus until a criterion of 18 correct responses out of 20 trials was reached. The left-right position of St was varied in accordance with Gellerman's series.

Overtraining and Reversal. As Ss reached criterion they were assigned to either the Overlearning $(O)$ or Control (C) condition. The day after reaching criterion, $\mathrm{Ss}$ in $\mathrm{C}$ condition were given reversal training (i.e., reinforced for approaching black) following the same conditions and criterion used in original training. Ss in condition $\mathrm{O}$, were given 100 additional (overtraining) trials at the rate of 10 per day, and then were given reversal training in the same manner as were the condition C Ss. 
Table 1. Means of Response Measures in Reversal

\begin{tabular}{lcccc} 
& \multicolumn{2}{c}{$\begin{array}{c}\text { Entry } \\
\text { Overlearning Control }\end{array}$} & \multicolumn{2}{c}{$\begin{array}{c}\text { Non-Entry } \\
\text { Overlearning Control }\end{array}$} \\
\hline Trials to Criterion & 47.5 & 63.8 & 38.8 & 45.0 \\
Errors to Criterion & 17.5 & 27.5 & 10.3 & 15.3 \\
Perseverative responses & 7.9 & 6.4 & 3.4 & 4.3 \\
Position days & 0.38 & 1.75 & 0.25 & 1.00 \\
\hline
\end{tabular}

\section{Results}

The mean trials to original criterion for the EntryOverlearning, Entry-Control, Non-Entry Overlearning and Non-Entry Control conditions were: 40.0,43.8, 38.8 and 40.0 respectively. A 2 by 2 analysis of variance indicated no significant differences among these measures. Similarly, the analysis of errors to original criterion indicated no significant effects. Thus, the groups were well matched and the E-NE conditions did not affect speed of original learning.

Table 1 gives the mean number of trials and errors to reversal criterion for the various groups. The Overlearning Condition resulted in fewer trials, $F=$ $9.38, \mathrm{df}=1 / 28, p<.005$, and fewer errors, $F=12.43$, $\mathrm{df}=1 / 28, \mathrm{p}<.005$, to reversal criterion than the Control Condition. Group NE reached reversal criterion in fewer trials, $F=14.00, d f=1 / 28, p<.001$ and with fewer errors, $F=20.99, \mathrm{df}=1 / 28, \mathrm{p}<.001$ than Group $E$. The interaction was not close to a significant level.

The number of perseverative errors (consecutive errors before the first correct reversal response) was greater in Group $E$ than in Group $N E, F=9.13, d f=1 / 28$, $\mathrm{p}<.01$ (see Table 1). No other differences were significant.

Any day on which S made $80 \%$ or more runs to the same position was designated a position day. There were more days of position responding in the Control Condition than in the Overlearning Condition, $F=7.63, \mathrm{df}=$ $1 / 28, p<.025$ (see Table 1). No other effect was significant.

\section{Discussion}

Paul's (1965) speculation that the E and NE conditions may differentially affect the overlearning reversal effect (ORE) was not supported since the ORE was found and did not interact with training conditions. However, the notion that $\mathrm{E}$ and $\mathrm{NE}$ conditions significantly affect reversal learning was supported, and seems to be in agreement with studies of the effect of obstructing a running response upon extinction in a runway situation (Klugh, 1961).

In view of the difficulties of obtaining the ORE (Paul, 1965) it is not clear what we did "right" here. Perhaps the relatively large reward magnitude used was responsible (Theios \& Blosser, 1965; Sperling, 1965). It may be worth emphasizing that all Ss had white as the original $S+$ and were reversed to black. Preliminary observations in our laboratory have suggested that, under our experimental conditions, an ORE is more likely to be obtained when animals are reversed to black from white than vice versa, and that this effect may be dependent upon conditions which affect relative ease of learning with $\mathrm{B}+$ compared to $\mathrm{W} \pm$.

\section{References}

Klugh, H. E. Speed of running in extinction as a function of differential goal-box retention time. J. exp. Psychol., 1961, 61, 172177.

Mackintosh, $\mathbf{N}$. J. Extinction of a discrimination habit as a function of overtraining. J. comp. physiol. Psychol., 1963, 56, 842-847.

Paul, C. Effect of overlearning upon single habit reversal in rats. Psychol. Bull., 1965, 63, 65-72.

Paul, C., \& Havlena, Joan. Effects of overlearning and spatial delay of reinforcement upon a discrimination reversal. Psychol. Rep., 1965, 16, 79-83.

Reid, L. S. The development of noncontinuity behavior through continuity learning. J. exp. Psychol., 1953, 46, 107-112.

Sperling, Sally E. Reversal learning and resistance to extinction: A review of the rat literature. Psychol. Bull., 1965, 63, 281-297.

Theios, J., \& Blosser, D. The overlearning reversal effect and magnitude of reward. J. comp. physiol. Psychol., 1965, 59, 252257.

Hotes

1. This study was supported by grant GB2782 from the National Science Foundation. Appreciation is expressed to L. Meyers and S. M. Plaut for conducting this experiment.

2. Three "deviant" Ss were discarded from the overlearning-entry group, and replaced by additional Ss. The deviant Ss scores would have contributed towards an interaction between method and degree of training. 